\title{
Called to Respond
}

\author{
by Maureen J. Smith
}

The Canadian Jesuit Refugee Programme hosted the conference "Called to Respond: Refugees and the New Canadian Reality" on October 28-30. The objective was to develop a working strategy on options to continue supporting refugees. Given the ambiguity of how the new legislation will be manifest in practice, our "new reality" is currently a largely unknown quantity. Clearly, in these circumstances, the process of developing a strategy is dynamic in nature since strategizing must anticipate the need to respond to reality as it unfolds.

\section{The Participants and the Process}

The eighty-five conference participants, assembled from across Canada to face this challenge of strategizing on options to support refugees, were mainly the front-line workers: NGO staff and volunteers, concerned and active individuals, and legal aid lawyers. Within this group there was a continuum of familiarity with refugee issues from the sweeping appreciation of refugee-related affairs of the Director of the Inter-Church Committee on Refugees whose knowledge results from a lengthy and intense involvement in this sphere, to the fledgeling, though equally genuine, acquaintance with the issues of a housewife who, by circumstance of responding to a friend's request to accommodate a newly arrived refugee couple in her home, has become aware of the need to respond to the refugee crisis. It was with this collective wealth of experience, consciousness, commitment and concern that the participants entered into the process of developing strategy.

Strategizing focused on four options which the conference participants acknowledged as being the most crucial components in a comprehensive strategy to continue refugee support work in our current situation. The four strategy options were Civil Disobedience, Monitoring the System, the Court Challenge, and the Overseas Situation.

A thread running through all of the discussions was the issue of mobilizing public opinion as a key element in the effectiveness of strategies to support refugees. This concept provides an essential focus for the comprehensive strategy.

In the development of strategy options, participants identified basic operative needs for initiating and sustaining implementation of these strategies. These basic needs, namely, co-ordination and information, delineated the parameters for a contingency plan, in the sense of making initial preparations required to provide the groundwork on which the overall strategy and its components will be erected and further developed in response to the unfolding of the Canadian reality.

The development of strategy was conducted in workshops corresponding to the four enumerated options. In addition, a working group on Refugee Women's Issues formed to articulate specific concerns which were integrated into the workshops. Summaries of the workshop conclusions follow.

\section{Civil Disobedience and Non-violent Resistance}

The dilemma of the uncertainty of the enforcement of the new legislation was nowhere more prevalent than in the Civil Disobedience Workshop. With the Detention and Deterrents Law (Bill C-84) having been enacted as of August 10, 1988, we are now facing a situation where,

"every person who knowingly organizes, induces, aids or abets, or attempts to organize, induce, aid or abet the coming into Canada of a person who is not in posesesion of a valid and subsisting visa, passport or travel document where one is required by this Act or the regulations, ts guilty of an offence and is liable

a) on conviction on indictment, to a fine not exceeding ten thousand dollars or to imprisonment not exceeding five years, or to both," (Section 94.1)

This impacts directly on front-line workers who continue to be involved in assisting refugees to come to Canada to claim status. Where refugee workers have consciously opted to persist in their efforts, despite the new legislation, they are de facto engaged in civil disobedience. Although the law regarding "aiding and abetting" is currently in place, it is unclear how and under what circumstances it will be enforced.

In addition, there was considerable deliberation on the use of non-violent resistance to draw national attention to the refugee crisis at both the global and domestic scale, and, in particular, to protest the new legislation. The objective of a strategy of non-violent resistance is to increase public awareness, consequently mobilizing public opinion and fostering broad-based participation in favour of remedying the existing legislation.

Key considerations for organizing such action include the need for careful, clear action; training to ensure the nonviolent nature of action; national co-ordination; and managing the traditionally problematic involvement of the media in publicizing resistance action. Also identified was the necessity of creating support bodies to organize a fund for payment of ensuing legal fees and fines, and to provide moral support to those charged and/or convicted of offences.

The participants of the Civil Disobedience Workshop proposed the formation of a National Network which will: 1) assist refugees,

2) change the laws by co-ordinating nonviolent resistance through action by local groups.

Conference participants agreed to submit this proposal to their respective organizations for consideration. Representatives from these organizations will be meeting at the Canadian Council for Refugees conference in November to plan national action. 


\section{Monitoring the System}

With the enactment of the amendments to the Immigration Act, as delineated in Bill C-55, officially slated for January 1,1989 , the Monitoring the System Workshop participants identified the need to scrutinize probable problematic practices arising from the new legislation in order to ensure protection of individual refugees and to provide the documentation necessary for a legal challenge to the legislation. Key elements required for an effective monitoring programme were specified.

Monitoring has two objectives. The first objective is to protect refugees on an individual basis by observing the proceedings so as to be aware of, for example, the need to advocate that a claimant who requests legal representation is in fact provided with the same. The second objective of monitoring is to collect documentation of the new practices. This body of documentation will provide the legal community with data, allowing them to discern patterns of practice that indicate defects in the legislation, resulting in systematic discrimination against specific types or groups of refugees.

Requirements for establishing an effective monitoring system revolve around accessing information and compiling documentation. Workshop participants stressed the need to access all available sources of information on the impact of the new legislation on refugee claimants. This includes establishing links with counterpart organizations in the United States and the refugee community to maximize detection of occurrences where new practices jeopardize refugees. Equally important is the need to establish a system of documenting the new practices. The system must ensure easy access by the legal community to the compiled data for use in preparing challenges to the legislation in the courts. In addition, as part of a strategy to provide individual protection, the participants recognized the need to develop and distribute guidelines for prospective claimants advising them of appropriate action when making their claim.

\section{The Court Challenge}

Several court challenges to the new legislation are currently being prepared, including one by the Canadian Council of
Churches which will challenge "those lifethreatening sections" of the new Act on the grounds that they are unconstitutional. Undoubtedly, the legal community will be making many challenges as cases arise. Equally certain is the fact that the process of legal contestation will be protracted.

The objective of the court challenge is to ultimately remedy the legislation so that genuine refugees are guaranteed protection. Workshop participants concurred that it is essential to mobilize public opinion in order to provide momentum to the legal contestation and also, so that when the time comes to reformulate the policy, the demands of the Canadian public, for a just policy, will be heard.

Capturing the support of the public imposes on the front-line workers the formidable task of translating the court challenge, and the reasons for it, into a popular, grass-roots campaign. This involves sensitizing Canadian citizens to the particularly vulnerable and unjust situation experienced by refugees both in terms of the conditions which led to their flight and of their enduring hardship due to the failure of the international community to effectively respond to their plight. The new restrictive refugee policy of the Canadian Government, which perpetuates the injustice suffered by refugees, must be presented to the public as symptomatic of a generally restrictive trend in government policy which impacts on all Canadian citizens.

A well-conceived popular education campaign is needed to arouse the consciousness of the Canadian public. This necessitates the development of popular resources which will explain the issues relevant to the court challenge in a manner comprehensible to the lay person. Organization is required to initiate and coordinate action at the community level and also in order to develop links with progressive sectors of society who can provide support to the popular movement surrounding the court challenge.

\section{The Overseas Situation}

The workshop on the overseas situation dealt with strategy on two issues; root causes and sponsorship.

In developing a strategy option to address root causes, workshop participants emphasized the need to investigate Canada's involvement in refugee producing situations both from the point of view of causal factors and that of management possibilities. It is imperative that Canadian links with the Third World, where the vast majority of refugees originate, be examined to determine ways in which we as a nation influence refugee production. This includes an evaluation of trade practices, foreign policy, development initiatives, and involvement in transnational corporations, all of which affect the social, economic, and political stability of potential refugee producing countries.

On the opposite side of the coin, investigation is required on the subject of Canada's potential role in minimizing the production of refugees through positive intervention initiatives. Possibilities for this role include diplomatic initiatives, such as lending legitimacy to regional conflict resolution accords by the granting of official recognition, and perhaps providing human rights observers to monitor volatile situations.

The findings of these investigations must be presented to the public in an effort to raise their awareness and, thereby, mobilize their concern to affect change. The findings must also be addressed to the government to influence policy decisions.

Workshop participants who strategized on sponsorship, proposed the use of private sponsorship as a means of bringing refugees to Canada in an effort to offset the impact of the new legislation in restricting the admittance of claimant refugees and government sponsored refugees. This was proposed as an ameliorating tactic while the court challenge proceeds in its efforts to remedy the legislation. To counter the lengthy wait involved in the security screening process, it was suggested that use of the Minister's permit, which circumvents the screening. be strongly advocated, especially for refugees in particularly risky situations. There is also a need to identify a pattern of which refugees are refused sponsorship, in order to detect defects in the legislation which should be contested in the courts.

\section{Towards a Comprehensive Strategy}

In the process of developing strategy options, one key concept and two basic operative needs assumed distinction as essential components for the development of a comprehensive strategy. 
The concept of public opinion mobilization was acknowledged by the conference participants to be the principal focus in a comprehensive strategy that will fundamentally transform the situation facing refugees seeking asylum in Canada. The question of working for just treatment of refugees is, and must be seen to be, an issue of fundamental human rights, the restricted protection of which, as is inherent in the new legislation passed by the Canadian Government, has direct and profound implications for the security of rights of Canadian citizens. In order to successfully continue working to support refugees in our present context, while simultaneously campaigning for a refugee policy which reflects the Canadian public's concern for the uncompromised observation of the inalienable rights of refugees, it is necessary to foster broadbased public support. National concern can be rallied if Canadians are prompted to equate the vulnerability of refugees, vis-a-vis the increasingly restrictive policies, with their own vulnerability, in the context of the current trend towards more restrictive government policy in general.

The mobilization of public opinion necessitates a well-administered and well-conceived campaign to educate the Canadian public. As a key focus in the comprehensive strategy to continue supporting refugees, public opinion mobilization requires that there be a solid base in terms of organization and access to information.

The two basic operational needs identified as essential for implementing the strategy options and also for the mobilization of public opinion are coordination and information. The conference participants recognized the need to establish a co-ordinating body that will construct the ground work on which strategy will be erected, as well as to act as an umbrella to existing organizations. This body would co-ordinate action nationally and provide a link between organizations to facilitate the collection and dissemination of resources required by the frontline workers.

Co-ordination could be mandated to an already existing organization or to a new body created specifically for this purpose. The responsibility for instituting this co-ordination function is most appropriately that of the organizations currently involved in front-line work with refugees. Action is urgently needed to affect this.
The second operative need of frontline workers for the implementation of the proposed strategies is information. This includes, among other things, documentation of cases once the new legislation is enacted in 1989, analysis of the conditions in refugee producing countries, and information geared to public education on refugee issues. A system must be established to which the front-line workers can both contribute and have easy access to a collective depository of information. The proposed co-ordinating body appears to be the most apt organizational framework in which the logistics of an information system can be accommodated. The frontline community must take action to develop an information system that will avail them of the tools required to implement strategies.

\section{Sources of Information}

While the front-line workers can contribute some of the information needed, such as documentation of cases, links to other sectors will provide other sources of information. For instance, background information on refugee producing countries can be tapped from centres involved in area studies and organizations working in the field. Conference participants identified academics engaged in refugee studies as a source of analysis of the data and as contributors of prediction of probable developments and prescription of appropriate action based on the data.

Academics involved in refugee studies and front-line workers share a common objective of (in the final analysis) assisting refugees. Whether one takes a direct, "hands-on" approach or an indirect, "conceptualization of the issues" approach is inconsequential to one's commitment to work towards that objective. In spite of there being a common objective, there is a very real gap between the work of the academic community and that of the frontliners which can and should be bridged.

The conference participants, representing the interests of the front-line community, expressed a hunger for information, especially for data that has been analyzed and the ensuing prediction and prescription based on the data. This demand for information indicates a practical nexus of the endeavours of the academics and the front-liners.

A large number of the conference participants subscribe to, or belong to ongani- zations which subscribe to, this periodical, Refuge. They also attend workshops and conferences on refugee issues to which academics are invited to contribute. Through these fora, the means of supplying the desired information exists. The academic community, on the basis of its common objective with the front-line workers, has a responsibility to respond to this situation in concrete terms.

Herein lies a challenge to academics involved in refugee studies to respond to the needs of their more practically-oriented counterparts in the collective effort to assist refugees. The challenge is this: to contribute to the existing fora the information and analysis resulting from their research which is oriented to the development of the strategies identified by the front-liners; namely, Civil Disobedience, Monitoring the System, the Court Challenge, and the Overseas Situation. They are also invited to give consideration to the weaknesses, and make suggestions for the strengthening, of this framework of strategies.

\section{Conclusions}

Conference participants successfully engaged in developing strategy on four options; Civil Disobedience, Monitoring the System, the Court Challenge, and the Overseas Situation. They identified as pivotal in the comprehensive strategy, the mobilization of public opinion in support of a refugee policy which genuinely observes our obligation to protect refugees. They also outlined two basic operative needs required to support strategies designed to assist refugees. These needs are that of national co-ordination and supporting information.

The front-line community needs to take action on these proposals. All organizations and individuals engaged in efforts to assist refugees have a responsibility to act in solidarity by contributing to the process according to their respective expertise. The challenge of devising and instrumenting ways of continuing to support refugees in our new, and yet uncharted, reality is one of urgency and one to which we are indeed "Called to Respond".

Maureen J. Smith, a graduate student in Interdisciplinary Studies, is the Public Relations Co-ordinator of the Centre for Refugee Studies at York Unioersity. 